\title{
The absorption of carbenoxolone administered orally as a positioned-release capsule
}

\author{
W. E. LINDUP, D. V. PARKE, AND D. COLIN-JONES \\ From the Biochemistry Department, University of Surrey, and University College Hospital \\ Medical School, London
}

SUMMARY Carbenoxolone administered in a position-released capsule is as readily absorbed as when administered by tablets, although not necessarily from the same site. It is therefore reasonable to suppose that the same systemic pharmacological actions will be observed with either preparation.

Carbenoxolone, the 3-0-hemisuccinate ester of $18 \beta$-glycyrrhetic acid, has been used with much success in the treatment of gastric ulcers (Doll, Hill, and Hutton, 1965; Horwich and Galloway, 1965; Montgomery, Mehta, and Lawrence, 1969) but was shown to have no healing effect on duodenal ulcer (Doll, Hill, Hutton, and Underwood, 1962). The ulcer-healing activity of the drug has been related to an increased production of gastric mucus (Goodier, Horwich, and Galloway, 1967) possibly brought about by an increased rate of synthesis of the glycoproteins of the gastric mucosal cells. Carbenoxolone administered orally is largely absorbed from the stomach (Downer, Galloway, Horwich, and Parke, 1970) and is excreted in the bile as conjugates with glucuronic acid. It has therefore been suggested that the healing of gastric ulcers by carbenoxolone is dependent on the drug penetrating the gastric mucosal cell, and hence, on the gastric absorption of the drug (Downer et al, 1970). The absence of any healing effect of orally administered carbenoxolone on duodenal ulcers may be due to insufficient quantities of the drug reaching the duodenum after gastric absorption, or to the lack of absorption of the drug at the ulcerated area of the duodenum. Furthermore, although the drug absorbed from the stomach is excreted via the bile into the duodenum, it is present in the bile as glucuronide conjugates which are unlikely to have the therapeutic properties of the parent compound even if some should find its way into the ulcerated proximal part of the duodenum.

A novel preparation of carbenoxolone in a positioned-release capsule which aims to deliver the drug into the duodenum, Duogastrone $R$, has now been produced. The preparation contains carbenoxolone sodium together with a carbon dioxide-generating mixture in a gelatin capsule specially treated so that it should rupture in the pylorus as the result of gaseous distension and deformation by peristaltic abrasion. Preliminary clinical trials with this preparation have shown considerable promise of efficacy in the healing of duodenal ulcer (Craig, Hunt, Kimmerling, and Parke, 1967; Perez, 1968). However, another trial, although showing promise after six weeks' treatment, showed no significant clinical advantage at 12 weeks and six months (Montgomery, Lawrence, Manton, Mendl, and Rowe, 1968).

Although it has been shown that carbenoxolone when administered orally is absorbed largely from the stomach as the non-ionized molecule (Downer et al, 1970) it cannot be assumed that $\stackrel{?}{?}$ when released directly into the duodenum the drug would be similarly absorbed from the small intestine. Carbenoxolone is a pentacyclic, terpenoid, carboxylic acid, with a molecular weight of 571, and the intestinal absorption of molecules of this size, which are likely to form ionic micelles, does not always readily occur. For example, certains sterols are poorly absorbed from the small intestine (Wiseman, 1964), although the intestinal absorption of sterols, like other drugs, has been shown to parallel their lipid solubility 
(Schanker, 1964). If it may be assumed that the mechanism of healing of duodenal ulcers by carbenoxolone would be the same as that suggested for gastric ulcers, the therapeutic efficacy of the positioned-release capsule would be dependent on the penetration of the carbenoxolone into the duodenal mucosa, and hence upon absorption of the drug from this area. Furthermore, if carbenoxolone is absorbed when the drug is administered as the capsule, the mineralocorticoid side effects that occasionally occur when the drug is given orally as tablets might also occur when the capsule is given. In fact this has now been observed (Forshaw, 1969; Montgomery et al, 1968).

The reason for the present investigation was therefore to ascertain, from determination of the plasma concentration of the drug, the extent and characteristics of absorption of carbenoxolone when administered in the positioned-release capsule. Radiological studies of the patients treated with the preparation were also carried out to determine the position and time of rupture of the capsule.

\section{Materials and Methods}

Isotopically labelled carbenoxolone was used in this investigation to enable the determination of very low concentrations of the drug in the blood plasma, for the radiochemical method as used in this investigation has a sensitivity of $0.1 \mu \mathrm{g}$. carbenoxolone $/ \mathrm{ml}$, several times greater than that of the chemical method (Coleman and Parke, 1963). Each capsule contained carbenoxolone sodium, labelled with ${ }^{14} \mathrm{C}$ in the $\mathrm{C}-1$ and $\mathrm{C}-4$ atoms of the succinate moiety $(50 \mathrm{mg}$ equivalent to $2.0 \mu \mathrm{C}$ of ${ }^{14} \mathrm{C}$, Iveson, Parke, and Williams, 1966), $200 \mathrm{mg}$ barium sulphate, and $15 \mathrm{mg}$ of sodium bicarbonate-citric acid mixture to generate carbon dioxide, in a specially hardened gelatin capsule. It was determined in previous experiments with human volunteers that in similar capsules a minimum content of $200 \mathrm{mg}$ barium sulphate was necessary for radiological detection of the position and bursting of the capsule.

One capsule was administered orally to each of three patients: P.B., a man aged 46, weighing $67 \mathrm{~kg}$; W.C., a man aged 31, weighing $57 \mathrm{~kg}$; and M.C., a woman aged 45, weighing $86 \mathrm{~kg}$; all of whom had radiologically confirmed duodenal ulcers. The capsule was swallowed in the early morning after eight hours without food, one cup of tea was taken three hours later, and a normal lunch was eaten four to five hours after the capsule. Each patient was examined radiologically at intervals to ascertain the location and time at which the capsule burst. Blood $(6 \mathrm{ml})$ was collected at intervals of 0.5 to 2 hours, in lithium-heparin bottles, and centrifuged at 2,000 revs/minute for 20 minutes to separate the plasma.

The blood concentrations of carbenoxolone, and/or any of its conjugates, were determined by measuring the total content of ${ }^{14} \mathrm{C}$ of the plasma, since it has previously been shown that carbenoxolone present in human blood is all associated with the plasma proteins and is reasonably stable, the ${ }^{14} \mathrm{C}$ label associated with the succinate moiety being liberated to a slight extent only by metabolism of the drug (Parke, 1968). Samples $(1.0 \mathrm{ml})$ of the blood plasma were added to $20 \mathrm{ml}$ of thixotropic dioxan scintillator of the following composition: Cab-O-Sil (Packard Instrument Co.) $50 \mathrm{~g}$, naphthalene $60 \mathrm{~g}$, 2,5-diphenyl oxazole (PPO) 4.0 g, 1,4-bis-2 (4-methyl-5-phenyloxazolyl) benzene (dimethyl POPOP) $0.2 \mathrm{~g}$, methanol 100 $\mathrm{ml}, 1,2$-ethanediol $20 \mathrm{ml}$ in 1,4-dioxan to make 1 litre. The samples were counted in a Packard Tri-Carb liquid scintillation spectrometer (model 3214), and counting efficiencies were determined by the channel ratio method (Bush, 1963) and by use of internal standards of ${ }^{14} \mathrm{C}$ toluene.

Pooled plasma from the patients $(5 \mathrm{ml})$ was extracted with chloroform $(2 \times 15 \mathrm{ml})$, the extract was concentrated to $0.1 \mathrm{ml}$ and then chromatographed on thin-layer plates of silica gel, fluorescent HF 254 (E. Merck, AG Darmstadt) in n-butanol-ammonia (sg 0.88$)(5: 1$ by volume). Reference samples of carbenoxolone $\left(R_{f} 0 \cdot 14\right)$ and enoxolone (18 $\beta$-glycyrrhetic acid) $\left(R_{f} 0 \cdot 40\right)$ were chromatographed at the same time. Carbenoxolone and enoxolone were detected by their quenching of background fluorescence under ultraviolet light (240-250 $\mathrm{m} \mu$, Hanovia Chromatolite). Glucuronide conjugates were detected by spraying the thin-layer plates with a mixture of $0.2 \% \mathrm{w} / \mathrm{v}$ naphthoresorcinol in acetone and phosphoric acid $9 \% \mathrm{v} / \mathrm{v}$ in water $(5: 1$ by volume, mixed as required), followed by heating at $120^{\circ}$ for $10 \mathrm{~min}$; glucuronides appear as violet spots on a buff-coloured background.

\section{Results}

Radiological examination showed that the capsules burst in the region of the pylorus in patient P.B. 1.5 hours after administration, and in patient M.C. after three hours. In the case of patient W.C. the capsule was not seen to burst and was intact after three hours but had disappeared (ruptured) after four hours.

The plasma concentrations of carbenoxolone reached a maximum of 8 to $9 \mu \mathrm{g} / \mathrm{ml}$ at 1.5 to two hours after rupture of the capsule in patients P.B. and M.C. (Fig.), and subsequently slowly declined. With patient W.C. the plasma concentration of carbenoxolone rose slowly and was still rising four hours after the capsule had disappeared and had probably ruptured. This slow attainment of 


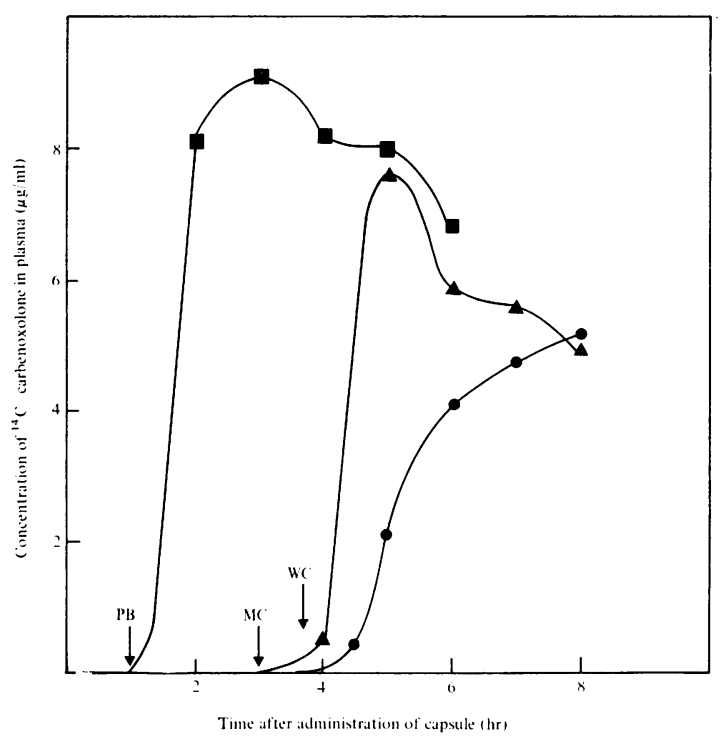

Fig. The plasma concentrations of ${ }^{14} \mathrm{C}$-carbenoxolone after oral administration of ${ }^{14} \mathrm{C}$-carbenoxolone in a positioned-release capsule, determined by measurement of the plasma radioactivity. The plasma concentration curves are for patients P.B., M.C., and W.C. Times of capsule when burst are indicated by the arrows.

the maximum plasma level of the drug, indicative of slow absorption, was probably due to dilution of the drug with the food that was taken shortly after the capsule had burst.

In the case of patients P.B. and M.C. the maximum plasma concentrations were equivalent to approximately $50 \%$ of the dose present in the circulating blood (Table). With patient W.C. the highest plasma concentration, namely, that at the termination of the experiment, was equivalent to only $24 \%$ of the dose in the circulating blood.

Thin-layer chromatography of the chloroform extracts of the plasma revealed the presence of carbenoxolone only. The hydrolysis product, enoxolone, was present in only trace amounts, and glucuronide conjugates of carbenoxolone and enoxolone were not detected.

\begin{tabular}{lllllll}
\hline Patient & $\begin{array}{l}\text { Weight } \\
(\mathrm{kg})\end{array}$ & $\begin{array}{l}\text { Maximum } \\
\text { Plasma } \\
\text { Concentration } \\
(\mu \mathrm{g} / \mathrm{ml})\end{array}$ & $\begin{array}{l}\text { Time from } \\
\text { Capsule Burst } \\
\text { to Maximum } \\
\text { Plasma Con- } \\
\text { centration }(\mathrm{hr})\end{array}$ & $\begin{array}{l}\text { Plasma } \\
\text { Volume }\end{array}$ & $\begin{array}{l}\text { Total Plasma } \\
\text { 14C-carben- } \\
\text { oxolone }(\mathrm{mg})\end{array}$ & $\begin{array}{l}\text { Dose in } \\
\text { Plasma } \\
(\%)\end{array}$ \\
\hline P.B. & 67 & $9 \cdot 1$ & 1.5 & $2 \cdot 7$ & 24.6 & 49 \\
M.C. & 86 & 7.6 & 2 & 3.4 & 25.8 & 52 \\
W.C. & 57 & 5.2 & $>4$ & $2 \cdot 3$ & 12.0 & 24 \\
\hline
\end{tabular}

Table Plasma concentration and degree of absorption of ${ }^{14} \mathrm{C}$-carbenoxolone administered in positioned-release capsules

${ }^{1}$ Assuming a mean plasma volume of $40 \mathrm{ml} / \mathrm{kg}$ body weight.

\section{Discussion}

In two of the three cases observed the capsule was seen to rupture in the region of the pylorus within one to three hours of administration. In these two fasting subjects the released carben- $\overrightarrow{\bar{B}}$ oxolone was rapidly absorbed giving rise to high plasma levels of the drug after an interval of only one to two hours from the rupture of the capsule. The drug was absorbed largely unchanged, as only carbenoxolone was detected in the blood plasma. The extent of absorption of $\%$ the drug in these two patients, as indicated by $\overrightarrow{0}$ the plasma levels, was comparable to that observed when carbenoxolone was administered $\vec{\omega}$ orally as tablets but the time patterns of the plasma concentration did not show the marked $\risingdotseq$ second maxima characteristic of the gastric $\vec{\longrightarrow}$ absorption of the drug (see Downer et al, 1970). This may be indicative of differences in the site or mode of absorption of the drug when given as the two different preparations.

In the third patient (W.C.) the capsule was not seen to rupture, and, although still intact at three hours after administration, had disappeared at four hours. In this case the absorption of the drug was considerably impaired, probably as the result of delayed rupture of the capsule and dilution of the drug with the meal which was taken after four hours. Thus a meal taken shortly after the rupture of the capsule is likely to delay absorption of the drug. It should be noted that the time taken for the capsule to rupture is variable (1.5-4 hours) in this study.

It is not possible in the present series to state with any certainty from which area of the gastrointestinal tract the carbenoxolone was absorbed, although in the two cases in which the capsules were seen to rupture in the area of the pylorus at least some absorption was likely to occur from the small intestines. However, as carbenoxolone has been shown to be readily absorbed when administered as the capsule it is reasonable to suppose that this preparation of the drug could give rise to systemic actions similar to those shown by the oral preparation, namely, increased production of gastrointestinal mucus and possible mineralocorticoid effects.

We are grateful to Dr J. E. Lennard-Jones for the interest he has shown in this investigation and for his clinical advice, and to Biorex Laboratories Limited for the supply of carbenoxolone and for the preparation of the positioned-release capsules.

\section{References}

Bush, E. T. (1963). General applicability of the channels ratio method of measuring liquid scintillation counting efficiencies. Analyt. Chem., 35, 1024-1029.

Coleman, T. J., and Parke, D. V. (1963). A spectrophotometric 
$m$ athod for the detzrmination of $\beta$-glycyrrhetic acid (enoxolone) and its esters in biological materials. J. Pharm. Pharmacol., 15, 841-845.

Craig, O., Hunt, T., Kim:rling, J. J., and Parke, D. V. (1967). Carbenoxolone in the treatment of duodenal ulcer. Practitioner, 199, 169-111.

Doll, R., Hill, I. D., and Hutton, C. (1965). Treatment of gastr.c ulcer with carbenoxolone sodium and oestrcgens. Gut , 6, 19-24.

Doll, R., Hill, I. D., Hutton, C.. and Underwood, D. J. (1962). Clinical trial of a triterpenoid liquorice compound in gas:ric and duodenal ulcer. Lancet, 2, 793-796.

Downer, H., Horwich, L., Galloway, R., and Parke, D. V. (1970). The absorption and secretion of carbenoxolone in man. J. Pharm. Pharmacol, 22, 479-487.

Forshaw, J. (1969). Muscle parisis and hypokalaemia after trcatment with Duogast zrone. Brit. med. J., 2, 674.

Goodier, T. E. W., Horwich, L., and Galloway, R. W. (1967). Morphological observations on gastric ulcers treated with carbenoxolone sodium. Gut, 8, 544-547.

Horwich, L., and Galloway, R. W. (1965). Treatment of gastric ulccration with carbenoxolone sodium: clinical and radio- logical evaluation. Brit. med. J., 2, 1274-1277.

Iveson, P., Parke, D. V., and Williams, R. T. (1966). The metabolic fate of ${ }^{14} \mathrm{C}$-carbenoxolone in the rat. Biochem. J., 100, 28P.

de Marcos Perez, V. M. (1968). Carbenoxolone sodium (Sanodin) in the treatment of duodenal ulcer. XIth Congress of Digestiye Pathology, Barcelona.

Montgomery, R. D., Lawrence, I. H., Manton, D. J., Mendl, K. and Rowe, P. (1968). A controlled trial of carbenoxolone sodium capsules in the treatment of duodenal ulcer. Gut, 9, 704-706.

Montgomery, R. D., Mehta, S. C., and Lawrence, I. H. (1969). Carbenoxolone in the long-term management of gastric ulcer. Practitioner, 202, 398-404.

Parke, D. V. (1968). Metabolic studies with carbenoxolone it $\mathbb{D}$ man and animals. In $A$ Symposium on Carbenoxolone Sodium: edited by J. M. Robson and F. M. Sullivan, C pp. 15-22. Butterworths, London.

Schanker, L. S. (1964). Physiological transport of drugs. Advanc. Drug. Res. pp. 71-106, 1

Wiseman, G. (1964). Absorption from the Intestine. Academic Press, London and New York. 